\title{
Research Paper: The Grammatical Abilities in a Speech Sample of Persian-speaking Children With Cochlear Implants
}

\author{
Safieh Samiee $^{1} \mathbb{D}$, Nahid Jalilevand ${ }^{1,2^{*}} \mathbb{D}$, Mohammad Kamali ${ }^{2,3} \mathbb{D}$, Yahya Modarresi ${ }^{4} \mathbb{D}$ \\ 1. Department of Speech and Language Pathology, School of Rehabilitation Sciences, Iran University of Medical Sciences, Tehran, Iran \\ 2. Rehabilitation Research Center, Iran University of Medical Sciences, Tehran, Iran. \\ 3. Department of Rehabilitation Management, School of Rehabilitation Sciences, Iran University of Medical Sciences, Tehran, Iran. \\ 4. Department of Linguistics, Institute for Humanities and Cultural Studies, Tehran, Iran.
}

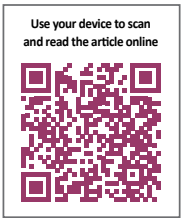

Citation: Samiee S, Jalilevand N, Kamali M, Modarresi Y. The Grammatical Abilities in a Speech Sample of Persian-speaking Children With Cochlear Implants. Iranian Rehabilitation Journal. 2020; 18(4):387-394. http://dx.doi.org/10.32598/irj.18.4.523.4

doi) http://dx.doi.org/10.32598/irj.18.4.523.4

(c) (i) (s)

Article info:

Received: 28 Nov 2018

Accepted: 16 Oct 2020

Available Online: 01 Dec 2020

\section{Keywords:}

Language Assessment, Remediation, and Screening Procedure for Persian (P-LARSP), Language sample, Cochlear implant, Persian, Word level inflections

\section{ABSTRACT}

Objectives: Studies reported that children with Cochlear Implant $(\mathrm{Cl})$ presented difficulties in grammatical acquisition. The Persian language is inflectional. The present study aimed to compare word-level inflections in the language samples of CI recipients and healthy-hearing children.

Methods: Thirty children were recruited in this descriptive-analytical cross-sectional study. The Language Sample Analysis (LSA) was used as a method of language production evaluation. Language samples were gathered using picture descriptions. A total of 3000 intelligible utterances were elicited and transcribed. An adaptation of the Language Assessment, Remediation, and Screening Procedure (LARSP) for Persian (P-LARSP), and the Mean Length of Utterance (MLU) techniques were used for the analyses of utterances.

Results: The stages of language development of CI recipients were lower than those of the healthy children. The obtained results indicated a significant difference between children with $\mathrm{CI}$ and healthy-hearing children in MLU $(\mathrm{P}=0.0001)$. Moreover, we found a significant difference between the study groups in the mean frequency of word-level inflections $(\mathrm{P}=0.0001)$.

Discussion: Children with CI use less word-level inflections, compared to their healthyhearing counterparts. 


\section{Highlights}

- Children with CI performed poorer in using grammar, compared to their healthy peers.

- The MLU (m), the MLU (w) demonstrated that grammatical development had deficits in the explored children with CI.

- Children with CI performed poorer in producing word inflections (inflectional morphology), compared to healthyhearing children.

- The current study data, based on the P-LARSP profile, revealed that the hearing-impaired children acquired inflectional morphology after cochlear implantation.

- The person agreement affixes were the most frequent word inflections used by the explored children.

\section{Plain Language Summary}

Children with hearing impairments can acquire syntax and morphology after cochlear implantation, but their abilities are poorer than their healthy peers. Language sample analysis is a method for expressive language assessment. The P- LARSP is a tool for the clinical grammatical analysis of language samples. The P- LARSP profile indicated that children with CI performed poorer in producing word inflections (inflectional morphology), compared to their healthy-hearing peers.

\section{Introduction}

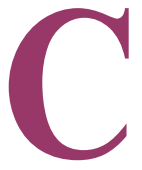

ochlear implantation is a common method employed in children with hearing impairments that helps them to learn oral language. It was reported that children with Cochlear Implant (CI) presented grammar acquisition [1]. Caselli et al. reported that young Italianspeaking children with $\mathrm{CI}$ indicated further morphosyntax errors in a sentence repetition task, compared to their age-matched healthy peers [2]. Szagun reported the Mean Length of Utterance (MLU) $=2$ for children with CI at 18 months post-implantation that provides positive implantation outcomes [3]. Guo et al. found that children with similar hearing age (hearing experience) presented similar abilities in using tense marking morphemes. Guo et al. suggested that $\mathrm{CI}$ recipients may learn tense making but with a late pattern [4].

Language Sample Analysis (LSA) is a method of evaluating expressive language. One of the most wellknown language development measures is the MLU. The MLU is an index of morphology and syntax development in children, i.e. used as a tool for measuring LSA. The average of morphemes per utterance equals MLU in morphemes MLU (m) and the average of words per utterance equals MLU in words MLU (w) [5]. Numerous researchers using LSA have concluded that children with $\mathrm{CI}$ generate problems in syntax and morphology $[6,7]$. Some Persian language researchers have also used LSA. Tavakoli et al. analyzed the language samples of Persian-speaking children with $\mathrm{CI}$ and their Normal-hearing $(\mathrm{NH})$ peers using the MLU as a measure for morphosyntactic development. They found a significant difference between children with $\mathrm{CI}$ at the chronological age of 5-6 years and their NH peers [8]. A tool for clinical grammatical analysis is LARSP [9]. The Language Assessment, Remediation, and Screening Procedure (LARSP) is a tool for screening, assessing, diagnosing, and therapy [10]. The LARSP is employed by speech and language clinicians for measuring language abilities in children with language delays or disorders. Using the LARSP profile for grammar and morphology analysis, the language sample of a child can comprehensively be analyzed. The LARSP was adapted to other languages, e.g. French and Turkish [11-15]. Numerous researchers have reported their research results using the LARSP profile [12, 16-19]. Yasar and Topbaş [12] used TR-LARSP to study the grammatical development of 15 Turkish 43-87-month-old children with Cis whose hearing age was $22-45$ months. They found significant differences in the morphosyntactic development of children with CI, compared with Typically Developing (TD) children. The tendency to use simple sentences was among the morphosyntactic characteristics of the CI group [12]. The LARSP was adapted to the Persian language in 1998 $[10,15]$. The P-LARSP profile is based on the language samples of three monolingual children, i.e. collected lon- 
gitudinally and signifies 7 language stages (stage I-stage VII). Samadi and Perkins concluded that the P-LARSP profile could be used to compare normal and abnormal language development in Persian-speaking children from stage I to the end of stage V [16]. Table 1 indicates the Language Assessment, Remediation, and Screening Procedure for Persian (P-LARSP) word level inflections. The P-LARSP word level consisted of grammatical morphemes or inflections, such as person agreement affixes, suffixes, prefixes, and comparative suffix. Based on the P-LARSP word level inflections, the examiners can elicit the grammatical morphemes was used in the language sample by the speaker.

The current study aimed to compare the morphosyntactic abilities between Persian-speaking children with CIs and their NH peers using MLU and the P-LARSP profile. We aimed to compare the word-level inflections of the P-LARSP profile between three groups of participants. The current study addressed the following points: whether the children with 36-48 months of hearing experience present morphosyntax abilities similar to those of the children at the chronological age of 36-48 months or not. The most frequently used kinds of word inflections by the children in the study groups.

\section{Methods}

This study was performed on monolingual Persianspeaking children with $\mathrm{CI}$ and $\mathrm{NH}$ children. The $\mathrm{CI}$ recipients were recruited from the 3 rehabilitation centers in Tehran City, Iran. Besides, the NH children were recruited from 2 kindergartens, i.e. randomly selected from Tehran City, Iran.

The research participants were 30 children (15 girls, 15 boys) who were divided into three study groups; group I: 10 children at the chronological age of 36-48 months who had cochlear implanted at least 1 year ago, group II: 10 children with CIs implanted 36-48 months ago (hearing age $=36-48$ months), and group III: 10 TD children without any hearing problems at the chronological age of 36-48 months. The scores of all developmental domains on the Age and Stage Questionnaire of healthy children were normal [20]. None of the children had a history of physical damage, seizures, brain damage, or any other disorders. The present study was part of the first author's MSc thesis, i.e. approved by the Research Ethics Committee of Iran University of Medical Sciences (Code: IR.IUMS.REC.1397.937). Before participating in the study, an informed consent form was signed by the children's parents.

Table 1. P-LARSP word-level inflections ${ }^{*}$

\begin{tabular}{cc}
\hline Category & Inflections \\
\hline Person agreement affixes & -am, -i, -e, -im, -id, -and \\
Prefix "mi" (present, present continuous, and future tense) & mi- \\
Possessive/Objective determiners & -am, -et, -esh, -mun, -tun, -shun \\
Negation prefix & na-/ne- \\
Prefix (subjunctive and imperative) & be-/bo-/biy \\
Plural Suffix & ha /a:/a:n \\
Object marker & Obj/o/ro \\
Definite suffix & def/e \\
Indefinite suffix & Indef/i \\
\hline The past participle inflection - e & Aux/pp/e \\
Clitic Ezafe/e/ey & e/ye \\
The comparative suffix -tar & tar \\
Superlative inflection - tarin & tarin \\
\hline *amadi and Perkins [16]
\end{tabular}

"Samadi and Perkins [16]

Mranian Rehabilitation Journa 
Language samples were gathered using picture descriptions for 20-30 minutes. The examiner requested all research participants to describe 30 multi-color pictures in sizes $20 \times 25 \mathrm{~cm}$ that presented daily events (e.g. children playing in a park or those at a birthday party). The children who were not interested in describing the pictures were excluded from the research.

The recording of the language samples was performed using a Kingston DVR-902 digital voice recorder in an appropriate room. Then, language samples were transcribed orthographically, occasionally, and phonetically, as required, by the examiner. A maximum of the first 100 intelligible utterances of each child was selected for analysis (a total of 3000 intelligible utterances of all children, 1000 utterances per group). The MLU (m) and MLU (w) were computed. Based on the P-LARSP profile, word-level inflections were elicited from language samples and counted, subsequently. The description of Persian grammar by Samadi and Perkins [16] was used to make decisions about grammatical morphemes, sentence structure, word order, nouns, verbs, pronouns, inflections, and other features of Persian grammar.

The current descriptive and analytic study was performed in SPSSV. 21. For every participant, the Mean \pm SD values of MLU (m), MLU (w), and the fre- quency of word-level inflections were calculated. A Kolmogorov-Smirnov test (K-S test) was conducted to determine whether the obtained data were normally distributed. To run between-group comparisons, the Mann-Whitney U test was used. Moreover, $\mathrm{P}<0.05$ was considered as the significance level.

The language samples of $20 \%$ of children were randomly selected and re-transcribed by another trained examiner. Based on the rules of P-LARSP, word-level inflections were elicited and recounted. The inter-rater point-to-point agreement reliability was examined. The inter-rater agreement for morphemes, utterances, words, and inflections indicated acceptable levels of agreement (>90\%) [21].

\section{Results}

In total, 30 children participated in the current study ( 15 boys \& 15 girls). Table 2 presents the Mean \pm SD values of the chronological age of the study participants in months. Two groups were of hearing-impaired children with CIs. The group I consisted of 36-48-month-old children who had used CIs for 1 year; group II included 10 hearing-impaired children who had had CI for 36-48 months; and group III covered 10 normal-hearing children aged 36-48 months. Table 2 indicates the Mean \pm SD age of CI surgery in hearing-impaired children.

Table 2. The mean and standard deviation values of the chronological age and the age of CI surgery

\begin{tabular}{cccccc}
\hline \multirow{2}{*}{ Groups } & \multirow{2}{*}{ N } & \multicolumn{2}{c}{ Mean \pm SD } & \multirow{2}{*}{ Min. } & Max. \\
\cline { 3 - 5 } & & Chronological Age & Age of Cl Surgery & & 36 \\
II & 10 & $42.9 \pm 5.66$ & $29.8 \pm 6.95$ & 24 & 36 \\
III & 10 & $66.7 \pm 6.63$ & $21.9 \pm 7.44$ & 12 & - \\
\hline
\end{tabular}

Group I: 36-48 months old deaf children after 1 year CI use;

Iranian Rehabilitation Journal

Group II: Deaf children after 36-48 months CI use;

Group III: 36-48 months old typically developing normal-hearing children.

Table 3. Language stages and the Mean \pm SD scores of MLUs and the frequency of word-level inflections in the study groups

\begin{tabular}{|c|c|c|c|}
\hline \multirow{3}{*}{ Language Stages } & \multicolumn{3}{|c|}{ Mean $\pm S D$} \\
\hline & Group I (N=10) & Group II (N=10) & Group III $(\mathrm{N}=10)$ \\
\hline & I-III & IV-V & V+ \\
\hline $\operatorname{MLU}(\mathrm{m})$ & $1.66 \pm 0.74$ & $4.00 \pm 1.50$ & $8.69 \pm 0.71$ \\
\hline $\operatorname{MLU}(w)$ & $1.31 \pm 0.34$ & $2.47 \pm 0.89$ & $5.07 \pm 0.47$ \\
\hline The frequency of word-level inflections & $18.90 \pm 21.37$ & $157.30 \pm 63.02$ & $327.90 \pm 63.90$ \\
\hline
\end{tabular}


Table 5. Statistics on between-group comparisons

\begin{tabular}{|c|c|c|c|c|c|c|}
\hline \multirow{2}{*}{ Groups } & \multicolumn{2}{|c|}{$M L U(m)$} & \multicolumn{2}{|c|}{ MLU (w) } & \multicolumn{2}{|c|}{ The Frequency of Word-Level Inflections } \\
\hline & Mean $\pm S D$ & $\mathbf{P}$ & Mean $\pm S D$ & $\mathbf{P}$ & Mean \pm SD & $\mathbf{P}$ \\
\hline Group I & $1.66 \pm 0.74$ & & $1.31 \pm 0.34$ & & $18.90 \pm 21.37$ & \\
\hline Group II & $4.00 \pm 1.50$ & 0.0001 & $2.47 \pm 0.89$ & 0.0001 & $157.30 \pm 63.02$ & 0.0001 \\
\hline $\begin{array}{l}\text { Group I } \\
\text { Group III }\end{array}$ & $\begin{array}{l}1.66 \pm 0.74 \\
8.69 \pm 0.71\end{array}$ & 0.0001 & $\begin{array}{l}1.31 \pm 0.34 \\
5.07 \pm 0.47\end{array}$ & 0.0001 & $\begin{array}{c}18.90 \pm 21.37 \\
327.90 \pm 63.90\end{array}$ & 0.0001 \\
\hline $\begin{array}{l}\text { Group II } \\
\text { Group III }\end{array}$ & $\begin{array}{l}4.00 \pm 1.50 \\
8.69 \pm 0.71\end{array}$ & 0.002 & $\begin{array}{l}2.47 \pm 0.89 \\
5.07 \pm 0.47\end{array}$ & 0.008 & $\begin{array}{l}157.30 \pm 63.02 \\
327.90 \pm 63.90\end{array}$ & 0.0001 \\
\hline
\end{tabular}

Iranian Rehabilitation Journal

The language samples of the children were analyzed by calculating MLU (m) and MLU (w). Table 3 lists the stages of language development and the Mean \pm SDscores of MLUs of children in the study groups. The stages of language development of the study participants were determined according to the P-LARSP chart [15]. The language development of children with CI in group II progressed to stage V; however, that of the group I fell below stage III. The grammatical abilities of the study groups were analyzed using the P-LARSP profile. Table 3 demonstrates the Mean \pm SD frequency of word-level inflections. Figure 1 shows the box plots of the results concerning the frequency of word-level inflections in the research groups. Table 4 reveals the Mean \pm SD frequency of word-level items in the speech samples of the examined children.

There were significant differences between the $\mathrm{NH}$ children and hearing-impaired children with $\mathrm{CI}$ in the mean scores of the MLU (m), the MLU (w), as well as the frequency of word-level inflections. Table 5 lists the values of the Mann-Whitney $\mathrm{U}$ test. A significant difference was found between the two groups of children with CI in the mean scores of the MLU (m). Moreover, significant dif-

Table 4. The Mean and SD frequency of word-level inflections in speech samples of children

\begin{tabular}{|c|c|c|c|c|c|c|}
\hline \multirow{2}{*}{ WOrd-Level Inflections } & \multicolumn{6}{|c|}{ Mean $\pm S D$} \\
\hline & Group I & Group II & Group III & Group I & Group II & Group III \\
\hline Person agreement affixes & 17.17 & 79.60 & 140.9 & 10.34 & 26.17 & 26.29 \\
\hline Possessive/ Objective determiners & 1 & 15 & 36.60 & - & 13.59 & 17.03 \\
\hline Prefix "mi" (present, present continuous and future tense) & 9.8 & 35.10 & 62 & 11.38 & 14.92 & 17 \\
\hline Prefix (subjunctive and imperative) be/bo/bey & 2.20 & 5.75 & 16.3 & 0.83 & 2.81 & 7.46 \\
\hline Prefix (negation) na/ne & 1 & 1.86 & 8.4 & - & 1.06 & 6.15 \\
\hline Object marker/Obj/o/ro & - & 7.88 & 16.9 & - & 5.89 & 5.06 \\
\hline Suffix (definite)/e & - & 2.57 & 7.30 & - & 2.51 & 10.58 \\
\hline Suffix (indefinite)/i & - & 2 & 2.33 & - & - & 2.30 \\
\hline Ezafe/e/ey & 1 & 4 & 6.22 & - & 2.34 & 4.14 \\
\hline Suffix (plurality)/ha/a:/a:n & - & 4.40 & 7.20 & - & 3.05 & 4.61 \\
\hline Auxiliary past participants/e & 3.14 & 12.20 & 25.7 & 1.95 & 4.02 & 12.62 \\
\hline Suffix (comparative) & - & - & 1.5 & - & - & 0.7 \\
\hline
\end{tabular}




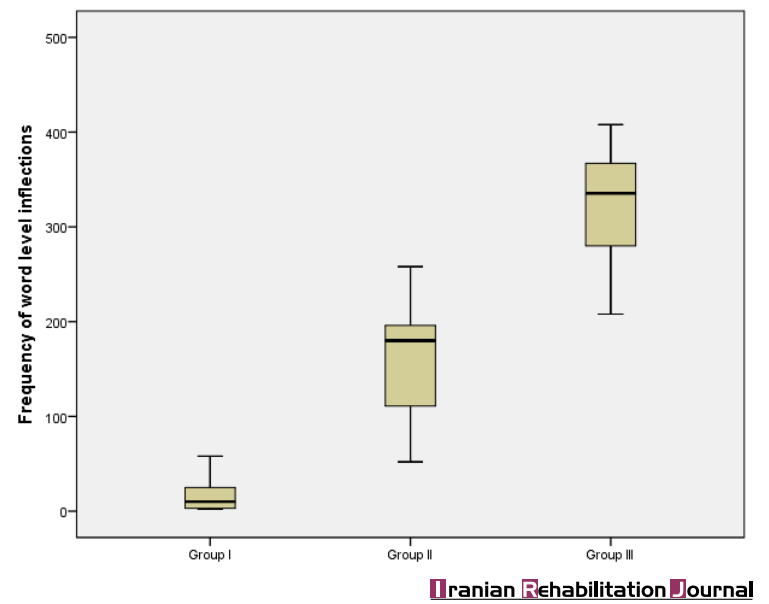

Figure 1. Box plots of results for the frequency of word-level inflections in the study groups

ferences were determined between the same groups in the mean frequency of word-level inflections $(\mathrm{P}=0.0001)$.

\section{Discussion}

The current study examined the morphosyntactic abilities of children with CI based on MLUs and P-LARSP profile. The current study aimed to explore whether hearing-impaired children can use word-level inflections after cochlear implantation similar to $\mathrm{NH}$ children or not. The collected results suggested that language development in hearing-impaired children, after 36-48 months of CI use had progressed to stage $\mathrm{V}$; however, the same value was under stage III for 36-48 months old children with hearing impairments one year after cochlear implantation. Thus, children with CI could acquire grammar and use grammatical items. However, the study findings indicated that children with CIs performed poorer in using grammar than their $\mathrm{NH}$ peers. This could be because the MLU (m), the MLU (w), and the frequency of word-level inflections were lower than those of the NH children. There were significant differences in the mean scores of the MLU (m), MLU (w), and the frequency of word-level inflections between the two groups of children with CI (the hearing age of two groups of children was not similar). Thus, morphosyntactic abilities in long-term CIs user hearing-impaired children were better than that of those who received CI recently. However, the obtained data indicated that morphosyntax abilities in the children who had 36-48 months of hearing experience significantly differed from morphosyntax abilities in children at the chronological age of 36-48 months. Accordingly, in this study, the MLU (m) and MLU (w) in children with CI demonstrated that their grammatical development had deficits. Rice et al. introduced MLU as an indicator of language development in children with language disorders $[5,22]$. The current study data were consistent with those of the previous studies on the morphosyntactic abilities of children with CI. According to previous studies, children with CI demonstrate poorer performance in syntax and morphology skills, compared to the TD children [23-27]. The results of a study on the grammatical development of Turkish children with CI were in line with the current study findings. Yasar and Topbaş compared TD Turkish children and CI children using the TR-LARSP. They reported that the morphosyntactic development of children with CI was limited, compared with that of the TD group [12].

Studies on Persian-language children with CI reported that children with CI presented fewer skills in morphosyntax than NH children. Tavakoli et al. compared MLU as a measure of syntax complexity between children with $\mathrm{CI}$ and NH children. They analyzed 50 utterances of each participant; they reported that MLU was not statistically different between children with CIs and $\mathrm{NH}$ children. However, MLU was statistically different between children with $\mathrm{CI}$ and $\mathrm{NH}$ children who were matched with chronological age (the hearing age of two groups of children was the same) [8].

Golestani et al. analyzed language samples using the Persian Developmental Sentence Scoring (PDSS) tool [28] to evaluate morphosyntactic abilities between hearingimpaired children using $\mathrm{CI}$ for 5 years and 5-year-old $\mathrm{NH}$ children (the same hearing age) as well as between 5-yearold hearing-impaired children with CI. Golestani et al. concluded that children with CIs can produce simple sentences; however, they observed significant differences between children with CIs and their $\mathrm{NH}$ peers in grammatical item scores. They reported that children with CIs had not acquired morphosyntactic skills as much as the NH children [28]. The current study findings also indicated that children with CI performed poorer in producing word inflections (inflectional morphology), compared to their $\mathrm{NH}$ children.

The person agreement affixes were the most frequent word inflections used by children; however, $\mathrm{NH}$ children used those more than CI recipients. These findings reflect that children with CI learn word inflections but use them less than NH children. The current findings were consistent with those reported by Guo and associates [4].Using a small sample size was the most important limitation of the present study. It is recommended to use a large sample size in future studies.

\section{Conclusion}

The morphosyntactical development of children after cochlear implantation usually differs from that of the NH children. The study findings indicated that children 
with CI perform poorer in using morphology than $\mathrm{NH}$ children. After cochlear implantation, over time, hearing-impaired children acquire morphosyntactic abilities; however, their grammatical abilities are more restricted than those of NH children. The person agreement affixes were the most frequent word inflections used by children. However, children with CI used those less than the NH children. Previous studies and the current study, using LSA and measures (MLU, PDSS.P-LARSP), demonstrated poor morphosyntax abilities in CI recipients. Therefore, speech and language therapists should consider morphosyntactic components in a language therapy plan for children with CI.

\section{Ethical Considerations}

\section{Compliance with ethical guidelines}

The present study was approved by the Research Ethics Committee of Iran University of Medical Sciences (Code: IR.IUMS.REC.1397.937). Before participating in the study, an informed consent form was signed by the children's parents.

\section{Funding}

The present study was part of the MSc. thesis of first author at Department of Speech and Language Pathology, School of Rehabilitation Sciences, Iran University of Medical Sciences, Tehran. Also The Vice-Chancellor for Research at Iran University of Medical Sciences supported the current investigation.

\section{Authors' contributions}

All authors contributed to conceptualization, methodology, investigation, writing original draft, writing-review, and editing as well as resources. Dr. Nahid Jalilevand contributed to the project administration and supervision.

\section{Conflict of interest}

The authors declared no conflicts of interest.

\section{References}

[1] Geers AE, Nicholas JG, Sedey AL. Language skills of children with early cochlear implantation. Ear and Hearing. 2003; 24(Suppl 1):46S-58. [DOI:10.1097/01.AUD.0000051689.57380.1B] [PMID]
[2] Caselli MC, Rinaldi P, Varuzza C, Giuliani A, Burdo S. Cochlear implant in the second year of life: Lexical and grammatical outcomes. Journal of Speech, Language, and Hearing Research: JSLHR. 2012; 55(2):382-94. [DOI:10.1044/10924388(2011/10-0248)]

[3] Szagun G. The acquisition of grammatical and lexical structures in children with cochlear implants: A developmental psycholinguistic approach. Audiology and Neurotology. 2000; 5(1):39-47. [DOI:10.1159/000013864] [PMID]

[4] Guo LY, Spencer LJ, Tomblin JB. Acquisition of tense marking in English-speaking children with cochlear implants: A longitudinal study. Journal of Deaf Studies and Deaf Education. 2013; 18(2):187-205. [DOI:10.1093/deafed/ens069] [PMID] [PMCID]

[5] Rice ML, Smolik F, Perpich D, Thompson T, Rytting N, Blossom $\mathrm{M}$. Mean length of utterance levels in 6-month intervals for children 3 to 9 years with and without language impairments. Journal of Speech, Language, and Hearing Research: JSLHR. 2010; 53(2):333-49. [DOI:10.1044/1092-4388(2009/080183)]

[6] Hansson K, Ibertsson T, Asker-Árnason L, Sahlén B. Phonological processing, grammar and sentence comprehension in older and younger generations of Swedish children with cochlear implants. Autism \& Developmental Language Impairments. 2017; 2:1-14. [DOI:10.1177/2396941517692809]

[7] Jung J, Ertmer DJ. Grammatical abilities in young cochlear implant recipients and children with normal hearing matched by vocabulary size. American Journal of SpeechLanguage Pathology. 2018; 27(2):751-64. [DOI:10.1044/2018_ AJSLP-16-0164] [PMID] [PMCID]

[8] Tavakoli M, Jalilevand N, Kamali M, Modarresi Y, Zarandy MM. Language sampling for children with and without cochlear implant: MLU, NDW, and NTW. International Journal of Pediatric Otorhinolaryngology. 2015; 79(12):2191-5. [DOI:10.1016/j.ijporl.2015.10.001] [PMID]

[9] Long HS, Channell RW. Accuracy of four language analysis procedures performed automatically. American Journal of Speech-Language Pathology. 2001; 10(2):180-8. [DOI:10.1044/1058-0360(2001/017)]

[10] Crystal D, Fletcher P, Garman M . The grammatical analysis of language disability: A procedure for assessment and remediation. London: Edward Arnold; 1976. https://books. google.com/books/about/The_Grammatical_Analysis_of_ Language_Dis.html?id=IpsLAQAAIAAJ

[11] Yaşar ÖC, Topbaş S. Profiling morpho-syntactical development of cochlear implanted children with TR-LARSP. Clinical Linguistics \& Phonetics. 2018; 32(3):181-92. [DOI:10.1080/026 99206.2017.1334231]

[12] Maillart C, Parisse C, Tommerdahl J. F-LARSP 1.0: An adaptation of the LARSP language profile for French. Clinical Linguistics \& Phonetics. 2012; 26(2):188-98. [DOI:10.3109/026 99206.2011.602459] [PMID]

[13] Ball MJ, Crystal D, Fletcher. Assesing grammar: The languages of LARSP. UK: Multi Lingual Matters; 2012.

[14] Jin L, Bee LO, Razak RA. C-LARSP: Developing a Chinese grammatical profile. In: Ball MJ, Crystal D, Fletcher P, editors. Assessing Grammar. The Languages of LARSP. Bristol: Multilingual Matters; 2012. [DOI:10.21832/9781847696397-014] 
[15] Hickey T. ILARSP: A Grammatical Profile of Irish. Clinical Linguistics \& Phonetics. 1990; 4(4):363-76. [DOI:10.3109/02699209008985497]

[16] Samadi H, Perkins MR. P-LARSP: A developmental language profile for Persian. Clinical Linguistics \& Phonetics. 1998; 2(2):83-103. [DOI:10.3109/02699209808985215]

[17] Guendouzi J. 'SLI', a generic category of language impairment that emerges from specific differences: A case study of two individual linguistic profiles. Clinical Linguistics \& Phonetics. 2003; 17(2):135-52. [DOI:10.1080/0269920031000061803 ] [PMID]

[18] Wren CT. Identifying patterns of syntactic disorder in six-yearold children. British Journal of Disorders of Communication. 1981; 16(2):101-9. [DOI:10.3109/13682828109011390] [PMID]

[19] Bedore LM, Leonard LB. Specific language impairment and grammatical morphology. Journal of Speech, Language, and Hearing Research: JSLHR. 1998; 41(5):1185-92. [DOI:10.1044/ jslhr.4105.1185] [PMID]

[20] Klee T, Stokes SF, Wong AMY, Fletcher P, Gavin WJ. Utterance length and lexical diversity in cantonese-speaking children with and without specific language impairment. Journal of Speech, Language, and Hearing Research: JSLHR. 2004; 47(6):1396-410. [DOI:10.1044/1092-4388(2004/104)]

[21] Vameghi R, Sajedi F, Mojembari AK, Habibollahi A, Lornezhad HR, Delavar B. Crosscultural adaptation, validation and standardization of Ages and Stages Questionnaire (ASQ) in Iranian Children. Iranian Journal of Public Health. 2013; 42(5):522-8. [PMCID]

[22] Peräkylä A. Validity and reliability in research based tapes and transcripts. In: Silverman D, editor, Qualitative Analysis: Issues of Theory and Method. London: Sage; 1997.

[23] Rice ML, Redmond SM, Hoffman L. Mean length of utterance in children with specific language impairment and in younger control children shows concurrent validity and stable and parallel growth trajectories. Journal of Speech, Language, and Hearing Research: JSLHR. 2006; 49(4):793-808. [DOI:10.1044/1092-4388(2006/056)]

[24] Geers AE, Moog JS, Biedenstein J, Brenner C, Hayes H. Spoken language scores of children using cochlear implants compared to hearing age-mates at school entry. Journal of Deaf Studies and Deaf Education. 2009; 14(3):371-85. [DOI:10.1093/ deafed/enn046] [PMID]

[25] Hawker K, Ramirez-Inscoe J, Bishop DVM, Twomey T, ODonoghue GM, Moore DR. Disproportionate Language impairment in children using cochlear implants. Ear and Hearing. 2008; 29(3):467-71. · [DOI:10.1097/AUD.0b013e318167b857] [PMID]

[26] Young GA, Killen DH. Receptive and expressive language skills of children with five years of experience using a cochlear implant. Annals of Otology, Rhinology and Laryngology. 2002; 111(9):802-10. [DOI:10.1177/000348940211100908] [PMID]

[27] Flipsen P, Kangas K. Mean Length of Utterance (MLU) in children with cochlear implants. The Volta Review. 2014; 114(2):135-55. [DOI:10.17955/tvr.114.2.744]

[28] Golestani SD, Jalilevand N, Kamali M. A comparison of morpho-syntactic abilities in deaf children with cochlear implant and 5-year-old normal-hearing children. International Journal of Pediatric Otorhinolaryngology. 2018; 110:27-30. [DOI:10.1016/j.ijporl.2018.04.019] [PMID] 